\title{
Mall Performance: Corporate, Retail, Restaurants and E-commerce Effects
}

\author{
Elisee Joseph ${ }^{1}$ \\ ${ }^{1}$ School of Business, Felician University, NJ, US \\ Correspondence: Elisee Joseph, School of Business, Felician University, NJ, US.
}

Received: January 17, 2019

Accepted: January 28, 2019

Online Published: February 12, 2019

doi:10.5430/ijfr.v10n2p1

URL: https://doi.org/10.5430/ijfr.v10n2p1

\begin{abstract}
Using continuous data from 2005-2016, the original purpose of this comprehensive research is to examine the relationships between mall-level sales per square foot and corporate performance. Through the use of discrete data, the alternative purpose of this research is to measure the overall performance of malls against the overall performance of individual stores, restaurants and e-commerce companies through the component of sales revenue, store productivity, real estate, and social media presence. Additionally, this researcher also implements a scoring model that can measure the performance of many individual retail institutions, e-commerce business, and restaurants. The results in this study suggest that mall performance is not correlated to corporate financial performance. However, this study generally shows a positive relationship between mall level performance and the overall performance of individual retail stores, restaurants and e-commerce businesses.
\end{abstract}

Keywords: commercial real estate, retail, restaurants, financial decision theory

\section{Introduction}

In the past decade, the overwhelming influence of online consumption and increasing interaction of the e-commerce marketplace has certainly made the conservative practice of shopping obsolete (Banerjee, 2017). The consistent technological evolutions of commerce that are caused by innovative marketing practices through digital channels have pressured executives at conservative shopping malls to modify their commercial policies in order to remain competitive and maximize profits. Oftentimes, strategists who can adjust their retail policies to promote an e-commerce friendly environment and cater to the core consumer market will be able to increase profits and foster growth.

This paper deals with the issue of implementing innovative quantitative strategies that cater to the productivity and wellness of commercial real estate companies can establish a heavy market presence for many retail companies. These cultivated strategies have important implications towards financial decision making through the interdependence of financial support from institutional stakeholders, the ability to efficiently remodel the short term and long-term objectives of each organization within the shopping center, and the intuition and anticipation of growth and profitability in the short run and the long run. The significance of this issue can help executives at these shopping malls and epicenters by increasing managerial efficiency while keeping up consumer's shopping patterns. The solutions to this issue can lead to an increase in profits and an increase in a commercial organization's value.

Most retail companies and shopping malls experience performance setbacks because corporate managers fail to reinvent certain policies that can effectively to increase profits. In this current economic climate, an abundance of major shopping malls is closing down due to the combination of low performance and increase competition (Sanicola, 2017).

This research paper has several contributions. First, this research study possesses a few suggestions from previous scholars and professionals that can enable strategists to successfully create models that may lead to an increase in profits and organizational growth through the accomplishments of short term and long-term objectives, great support from a coalition of shareholders and stakeholders, and a strong anticipation of positive performance in the future. Secondly, this researcher gathers financial information from the Securities and Exchange Commission (SEC) in order to analyze this information through JavaScript and use $\mathrm{R}$ to cultivate two quantitative models that support this researcher's theory throughout this paper. 
In theory, the empirical results of this research project should suggest that shopping centers with a high level of physical and technological presence in the retail industry tend to increase profits and foster firm growth. From a practical perspective, the results should be of interest to strategists and executives who plan on implementing responsible guidelines in order to maximize revenue and remain profitable while achieving high firm performance.

The remainder of this paper is structured as follows: The second section reviews previous research. The third section describes data collection, variables, and hypothesis. The fourth section of this paper presents the descriptive and inferential statistical models. The fifth section of this paper discusses the empirical results. The sixth section of this paper summarizes and concludes this study.

\section{Literature Review}

There are various research analysts and scholars who have contributed to the topic of retail performance and productivity. Hudson (2017) is one of the main authors who has made contributions to retail performance metrics. In this article called " 8 Ways to Measure Retail Performance and Productivity", Hudson (2017) provides eight important performance calculations that should be addressed when monitoring a retail shopping center:

\subsection{Measuring Performance of Selling Space}

\subsubsection{Sales per Square Foot}

Commonly useful for planning inventory purchases. Also used to calculate return on investment and rent on retail location:

$$
\text { Sales per square foot of selling space }=(\text { Total Net Sales }) /(\text { Square Feet of Selling Price })
$$

\subsubsection{Sales per Linear Foot of Self Space}

Useful for determining a product's (product category) share of space:

$$
\text { Sales per Linear Foot }=(\text { Total Net Sales }) /(\text { Linear Feet of Shelving })
$$

\subsection{Measuring the Performance of Inventory}

\subsubsection{Sales by Department or Product Category}

Useful for comparing product categories within a store. For instance, an athletic manufacturing store can see how the sales of the footwear department compared to the entire store's sales:

\subsubsection{Inventory Turnover}

$$
\text { Category \% of Total Store Sales }=\frac{\text { Category's Total Net Sales }}{\text { The Entire Store's Net Sales }}
$$

Useful to know if a retail store is overstocked or even under-stocked on a product:

$$
\text { Inventory Turnover }=(\text { Sale at Retail Value }) /(\text { Average Inventory Value at Retail Value })
$$

\subsubsection{Gross Margin Return on Inventory}

Provides an accurate picture of profitability compared to inventory turnover through a combination of metrics:

$$
\text { Gross Margin Return on Inventory =(Gross Margin in USD)/(Average Cost of Inventory) }
$$

\subsection{Measuring the Productivity of Staff}

\subsubsection{Items per Transaction/ Sales per Customer}

Provides information based on the average sales transaction:

\subsubsection{Sales per Employee}

$$
\text { Items per Transaction }=\frac{\text { Gross Sales }}{\text { Number of Transaction }}
$$

Useful performance metrics that determine the number of sales that a retail business need to generate when increasing human capital:

$$
\text { Sales per Employee }=(\text { Net Sales }) /(\text { Number of Employees })
$$

\subsubsection{Accessory Percentage}

Useful for understanding how well the employees are increasing sales. Depending on certain products, the ideal measurement for this metric is approximately $10 \%$ :

$$
\text { Accessory Percentage (\%) of Sales }=\frac{\text { Net sales }}{\text { Accessory sales }}
$$

After providing these retail performance measurements, Hudson (2017) argues that retail managers that can 
consistently monitor these metrics should be able to grow their business and avoid setbacks from bad decisions based on uncertain intuitions.

Nicasio and Stanley (2011) extend Hudson's (2017) metrics by providing additional key performance indicators among all retail shopping centers. In this article called "Key Performance Indicators- 10 Metrics for guiding and measuring and measuring store success", Nicasio and Stanley (2011) provide 10 distinct measurements that play a key role in performance. Like Hudson (2017), Nicasio and Stanley (2011) argue that sales per square foot, inventory turnover, and gross margin return on inventory (GMROI) are one of the major metrics that can be used to compare the performances of shopping malls.

\subsection{Other Performance Measurements}

Other performance measurements include foot traffic which refers to the number of people that are in the retail store for a particular period and the conversion rate which measures the percentage of customers who bought from the individual retail store. This performance indicator helps managers measure the performance of various departments within a retail store like accessories, merchandising, customer service and more. A low conversion ratio may indicate that this retail store is doing a great job at attracting customers to the store, but the customers are not quite connecting to the products within the store:

$$
\text { Conversion Rates }=\frac{\text { Number of sales transaction }}{\text { Gross traffic }}
$$

\subsubsection{Sales Count}

Sales count which refers to the number of transactions that are completed at a particular time; Average Transaction Value to Basket Value Ratio which demonstrates the average amount of money that a customer is spending at a retail shopping store or a mall. A high ratio indicates that the customers are spending money on luxurious and expensive products or the customers are buying large quantities of products at a given location.

\subsubsection{The Profit Margin}

$$
\text { Average Transaction value to Basket Value Ratio }=\frac{\text { Total Revenue }}{\text { Number of Transactions }}
$$

The profit margin in the key performance indicators refers to how much revenue is being generated after the cost deduction for each product where:

\subsubsection{The Product Returns}

$$
\text { Profit Margin }=\frac{\text { Gross Profit }}{\text { Total Revenue }} \times 100
$$

The product returns refer to the percentage of products that are returned. A high product return rate indicates major problems in product quality, customer services or even marketing where:

$$
\text { Product Returns }=\frac{\text { Number of Returns }}{\text { Number of Items }} \times 100
$$

\subsubsection{The Sell Through Percentage}

The Sell through Percentage metric refers to the percentage of units sold vs. how much products were available at the beginning of the month. This metric also helps managers make key decisions on which items should be sold:

$$
\text { Sell through Percentage }=\frac{\text { Number of Units Sold }}{\text { Beginning Inventory }} \times 100
$$

Based on the status of the retail company (or shopping center), strategists can determine which data is useful, while creating key models that can lead to better performance in the short-term and long-term future. In this research article called "Retail sale data and the evaluation of major retail centers", Ramsey (1994) provides different quantitative metrics that measures overall performance within the retail industry. In addition to the metrics of the mall-level sales per square foot, Ramsey (1994) also stresses the importance of analyzing individual store performance within every mall. The indication of individual store performance is useful when dealing with a large number of tenants and each department store's unique size. Individual stores can also be a good measurement for mall performance because these individual tenants can categorize through cluster analysis, depending on the types of items that are sold in these companies. Typical categories include women's apparel, men's apparel, shoes, gifts, gifts, special food, general food, restaurants, jewelry, music/electronics, and retail specialty. In the support of Ramsey's (1994) approach, this researcher will institute comprehensive data that involves mall-level and individual performance.

Although there are many quantitative metrics that can clearly evaluate the performance. There is an abundance of qualitative metrics that define a shopping center's success. Based on the article called "Six Factors that determine a Retail Mall's Success", the six important qualitative factors that can affect a shopping center's performance are a comfort, a diverse group of malls, luxury, mall essence, entertainment, and convenience. These factors can attract 
heavy traffic of satisfied customers depending on the number of profitable stores within the mall. Additionally, these qualitative factors of performance heavily depend on the marketing strategies of each retail tenants.

When it comes to the establishment of great marketing strategies, this researcher uses recent marketing literature from prominent scholars like Anderson (2006) and Berger (2017) to establish a qualitative approach within the retail industry. In this article called "How to be more influential", Berger (2017) provides four contemporary steps that allow marketers to be more successful in the modern economy. The four steps include being a chameleon, making consensus visible, uniqueness and being exposed. When it comes to the topic of a chameleon, Berger (2017) argues that managers should delicately pay attention to the language, behavior and facial expressions of other customers and employees. This step is very important when marketers are trying to establish relationships with their customers. Paying attention to the reaction and body language of customers can deepen social bonds and turn strangers into loyal customers.

Chris Anderson (2006) is one of the major scholars that have made contributions towards market segmentation, internet marketing, and technological innovation. In this book called The Long Tail: Why the Future of Business is Selling Less of More, Anderson (2006) uses different marketing strategies to increase profits and encourage firm growth. Throughout this book, Anderson (2006) uses analogous examples from Amazon, Yahoo and Apple to explain how products and services with low demand can achieve market success. Anderson (2006) effectively argues that products and services with low demand and sales volume can build a better market share than other products through a retailing strategy of selling a large amount of low performing items at a relatively wholesale price. As indicated earlier, there are many papers that are written in conjunction with the examination of the objective and marketing approach towards the retail shopping industry. Although these studies were conducted within various models and purposes, the results in previous studies suggest that there is a strong relationship between various mall level sales per square foot and other variables of performance and profitability among individual retail stores.

\section{Research Methods, Data Collection, Variables, Hypothesis}

\subsection{Research Methods}

This candidate uses secondary information to examine the relationship between mall level sales per square foot and mall performance by displaying geospatial information to describe the dataset and provide inferential implications between certain variables. In the initial dataset, there were many missing values within the independent variables. Therefore, this researcher uses a simplistic imputation method of the sample mean to replace these missing values with the respective average values of every continuous variable- making the regression model much stronger.

\subsubsection{Data Collection}

Initially, this researcher obtains a population of 1,009 universal malls in the United States. Using the geocoding API code along with the JSFiddle platform, this researcher was able to display a geographical location of every mall through the combination of HTML and JavaScript coding.

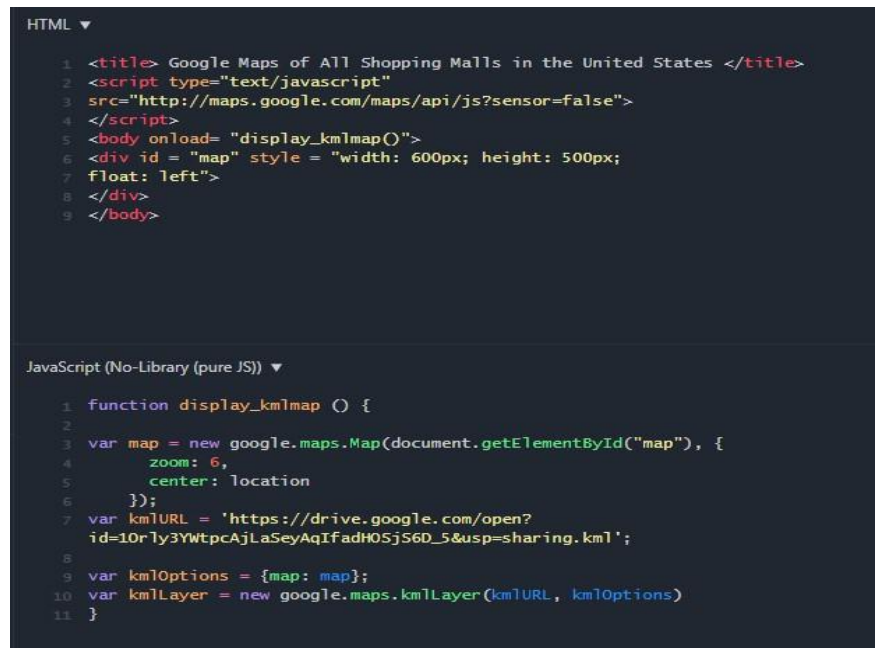

Figure 1. HTML/ Javascript code: universal malls within the United States 


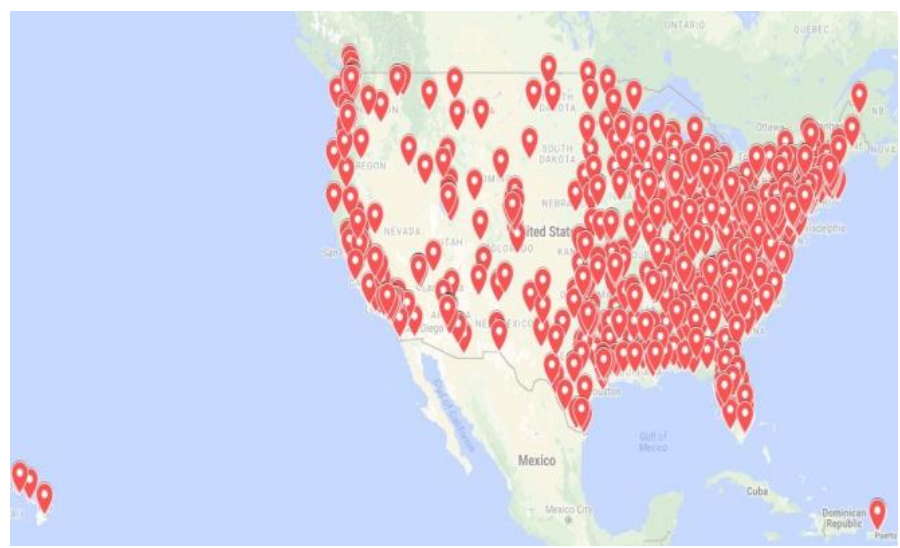

Figure 2. Geographical location of every mall in the United States (Note 1)

Based on the figures above, this researcher can make a solid argument that there is a heavy presence of competition among the east and south region of the United States. This measurement of competition may have some interesting implications for the overall performance of these shopping centers. Out of the population of 1,009 malls, this researcher was able to gather a time series historical (in sales per square foot) of 220 malls from three Real Estate Investment Trusts (REITs): CSL \& Associates Properties (CBL), Pennsylvania Real Estate Investment Trusts (PREITs) and Macerich (MAC). This researcher obtains a total of 3,730 different sales per square foot observations from $2005-2016$.

In addition to obtaining performance information from shopping centers, this researcher uses the Center for Research in Security Prices (CRSP) to collect time-series. This financial data from Retail stores, and restaurants (SIC Code: 5200-5990), consumer electronics companies (SIC Code: 7629), REITs (SIC Code: 6798), and multinational commercial Real Estate firms (SIC Code: 6512) to understand other factors that may affect the performance of all shopping centers within this project. When it comes to the overall sample size of companies that were found in the CRSP database, this researcher obtains a total of 3434 continuous observations among 437 companies from $2005-2016$. The highlighted securities markets that are selected in this project are the New York Stock Exchange (NYSE) and the Chicago Board of Trade (CBOT). The entities corresponding to the syntax of this crystal reporting code for this particular CRSP query is detailed below.

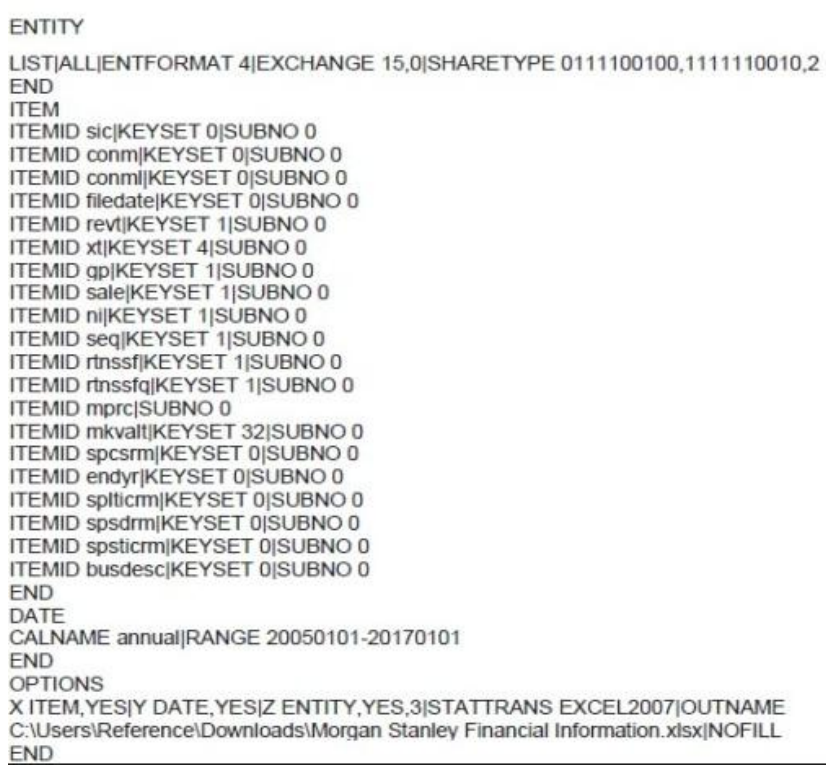

Figure 3. Syntax code: CRSP crystal report 
In agreement with Ramsey (1994), this researcher uses a wide-ranging dataset from eMarketer that contains financial information individual retail companies and restaurants. It is important to understand that the profitability metric of sales per square foot for all malls is one way to measure retail performance. But, the analysis of individual retail and e-commerce companies like Amazon, Best Buy, Target, Walmart, and Apple is a major component of performance in this project. As of the end of the fiscal year 2017, the overall dataset contains information 217 retail and e-commerce companies along with 84 restaurant chains. This secondary information on individual retail companies and restaurants are very important for this project because this researcher can implement a list of key factors that may affect the overall sales per square foot of the stores and restaurants in each shopping center.

There are two models in this project. First, this researcher will test the relationship between the given mall level performance and the information from corporate companies that are collected from the Center for Research in Security Prices (CRSP) in this research project. Secondly, this researcher will analyze the distinct potential relationship between mall level sales per square feet and the different variables that may affect the performance of the individual retail stores from 2016-2017.

\subsubsection{Description of Dependent and Independent Variables for Shopping Malls and Corporate Performance}

This paper covers various dependent, independent and control variables. This researcher uses the shopping mall's sales per square foot as the key dependent variable. The following independent variables that are used in this portion of the project are Gross Profit, Net Sales Turnover, and Total Stockholder Equity. In agreement with other scholars and analysts in the literature review section, this researcher believes that the net sales turnover and gross profit are two major components that should be taken into consideration in this particular portion of the project. A summary of the definition of variables can be found below in Table 1 .

Table 1. Summary of variables for first model

\begin{tabular}{ll}
\hline List of Variables for Model 1 & (Malls vs. Corporate Performance from CRSP data) \\
\hline Dependent Variable & Mall's Sales per Square Foot \\
\hline Independent Variables & Gross Profits \\
\hline Net Sales Turnover \\
\hline Total Stakeholder Equity \\
\hline & Location \\
\hline & Mall Size \\
\hline & Time (2005-2016) \\
\hline
\end{tabular}

3.1.3 Description of Independent Variables for Shopping Malls, E-commerce Corporations, Retail Stores, and Restaurants

The following independent variables that are used in this portion of the project are the average sales per square foot of all retail stores and restaurants, Average sales per store/restaurants, and the average social media presence. Social media is an important marketing component in e-commerce in any industry (Marbury, 2017). Digital platforms like Facebook, Instagram, YouTube and company websites can enable physical retail companies and e-commerce businesses to efficiently connect with their customers through digital internetworking platforms. Digital and social media platform can also expand a company's marketing platform- reaching millions of loyal supporters and potential customers. The researcher uses the 9 different digital and social media platforms to find each organizations' social media presence:

Digital and Social Media Presence $=($ Facebook Likes + YouTube Views + Website Visits $) /(1+$ Twitter Followers + YouTube Subscribers Pinterest Followers, Instagram Followers, Google Followers, LinkedIn Followers)

A summary of the definition of variables can be found below in Table 2 . 
Table 2. Summary of variables for e-commerce companies and retail stores, and restaurants

\begin{tabular}{ll}
\hline List of Variables for Model 2 & E-Commerce companies, Retail Stores, and Restaurants \\
\hline Dependent Variable & Mall level Sales per Square Foot \\
\hline Independent Variables & Stores and Restaurants Average Sales per Square Foot \\
\hline Total Revenue (in Millions) \\
\hline Average Sales per Store (or restaurants) \\
\hline Retail Store Sales (in Millions) \\
\hline Retail Store Sales Growth (in \%- from the previous year) \\
\hline Social Media Presence which includes the average of: \\
\hline Twitter Followers, Facebook Likes, YouTube Subscribers, \\
\hline YouTube views, Pinterest Followers, Instagram Followers, \\
\hline Google Followers, LinkedIn Followers, and Website Visits \\
\hline Location \\
\hline Number of Stores and restaurants \\
\hline Average Size of each Store and Restaurant (Square ft.) \\
\hline Time (2016-2017) \\
\hline Sectors \\
\hline
\end{tabular}

\subsubsection{Hypothesis}

This researcher postulates that there is a positive relationship between the mall-level sales per square foot and the independent metrics of the various other firms in the first model. Additionally, this researcher believes that there is also a positive relationship between mall level sales per square foot and the overall performance metrics of these corresponding e-commerce companies, retail stores, and restaurants.

\section{Results-Statistical Modeling}

In order to obtain descriptive statistics in both models, this researcher implements the observations into RStudio. The entire console code for is listed in section 4.1.

\subsection{R Code: Overall Data Import from Excel}

\#\#Dataset for continuous analysis 1: Malls vs. A wide variety of companies

library(readxl)

Morgan_Stanley_2018_Quant_Finance_Project_Final_Copy_

$<-$ read_excel("Morgan Stanley 2018 Quant Finance Project (Final Copy).xlsx",

sheet $=$ "Mall Sales PSF + CRSP Data")

view(Morgan_Stanley_2018_Quant_Finance_Project_Final_Copy_)

\#\#Dataset for Discrete analysis 2: Retail Stores, and Restaurants

library(readxl)

Morgan_Stanley_2018_Quant_Finance_Project_1_

$<$ - read_excel("Morgan Stanley 2018 Quant Finance Project (1).xlsx",

sheet $=$ "2016-17 Retail and Restaurants", skip = 1)

view(Morgan_Stanley_2018_Quant_Finance_Project_1_) 
4.2 Model 1- Measuring Mall Performance Against Corporate Performance Descriptive Statistics- Model 1 (Malls vs. Different Companies from CRSP Database)

The corresponding code and outputs for the descriptive statistics regarding the first model are listed below:

4.2.1 R Code: Descriptive Statistics for First Model

\# Descriptive Statistics of the Dataset

cor(Morgan_Stanley_2018_Quant_Finance_Project_Final_Copy_)

[c("Mall Store Sales psf (\$)",

"Gross Profit (Loss)", "Sales/Turnover (Net)", "Total Stockholders' Equity")])

Summary (Morgan_Stanley_2018_Quant_Finance_Project_Final_Copy)

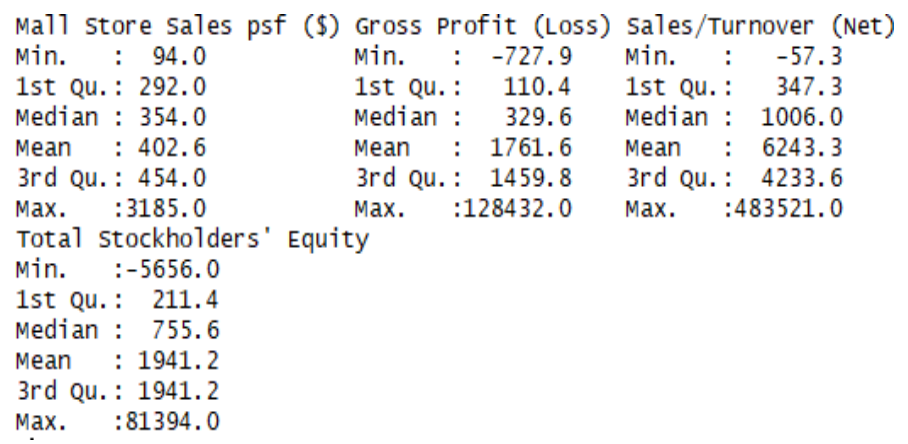

Figure 4. Descriptive statistics for the first model

Based on the descriptive output, this researcher can conclude that there is a huge dispersion of numbers in the Gross Profit, Sales turnover, and total stockholder equity. This observation may result in a weak association between the exploratory variables in this model.

\subsection{Inferential Statistics: Regression Modeling-Model 1 (Malls vs. Different Companies From CRSP Database)}

The following code and output below demonstrate the Pearson correlation between the dependent variable (Mall sales per square foot) and independent variables (Gross profit, Net Sales Turnover, and total stockholder equity). In order to implement a scatter plot in this model, this researcher reviews the dataset and disregards the other variables that are not needed for this analysis test (mall names, location and business descriptions of every public/private company that were compiled in the CRSP database.

\subsubsection{R Code: Scatter Plots for First Model}

\#Descriptive Statistics for variables in Model 1

pairs(Morgan_Stanley_2018_Quant_Finance_Project_Final_Copy_)

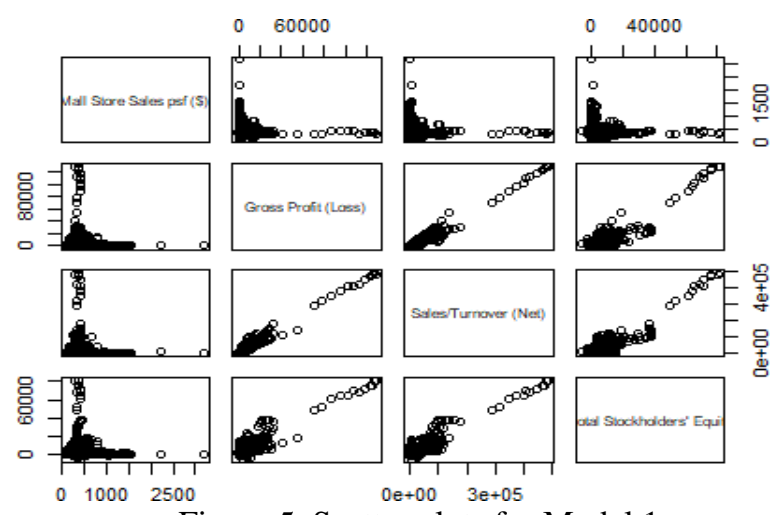

Figure 5. Scatter plots for Model 1 
Based on the information on the matrix scatter plots in Figure 5, this researcher can make a brief conclusion that the mall's sales per square foot have a slight negative (weak) relationship with the gross profits, sales/turnover, and total stockholder equity. In other words, mall performance is not really associated with the data that is obtained in the CRSP database.

In order to get a better understanding of the display of scatter plots in this model, this researcher uses a correlation function to obtain information on the strength and relationship between mall performance and the gross profit, sales/turnover and total stockholder equity of multiple companies and firms from the CRSP database. The corresponding codes of the correlation for Model 1 are shown below:

\subsubsection{R Code: Correlation Matrix for First Model}

\#\# Correlation matrix for the First Model using colors (blue = positive and red = negative) and numbers

ms <- cor(Morgan_Stanley_2018_Quant_Finance_Project_Final_Copy_)

\section{library(corrplot)}

corrplot(ms, method = "color")

$\operatorname{corrplot}(\mathrm{ms}$, method $=$ "number")

$\operatorname{view}(\mathrm{ms})$

The following diagrams demonstrate the quantitative strength and relationship between mall performance and certain corporate performance among all companies within the CRSP database:
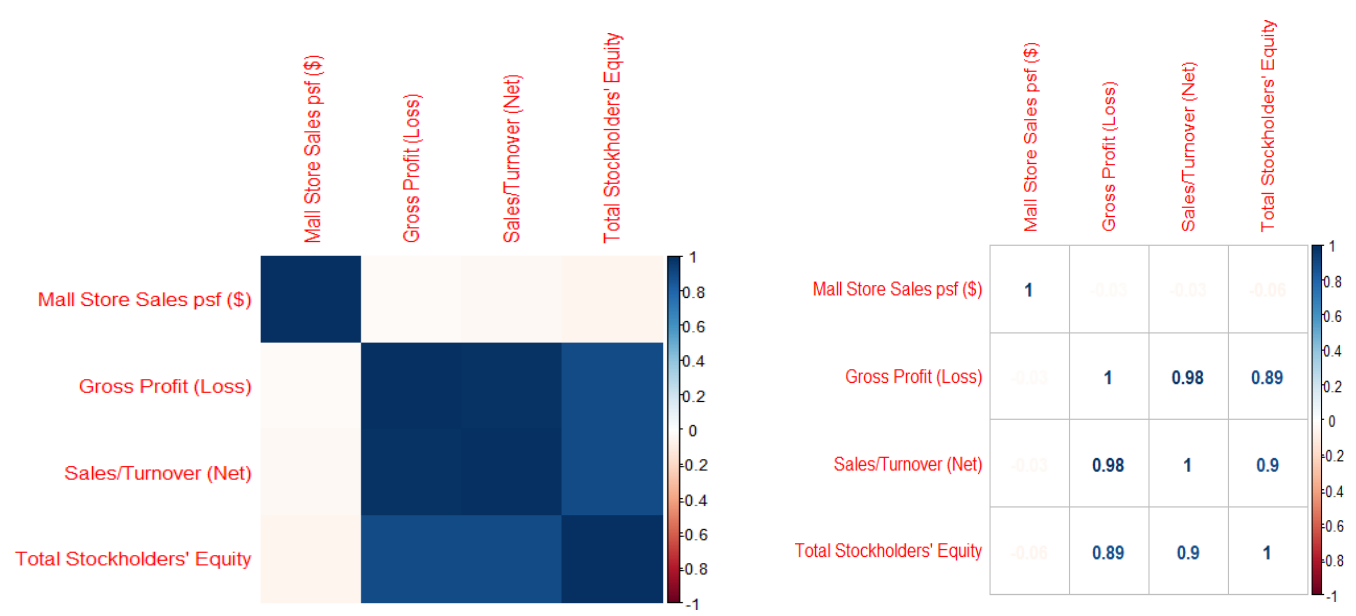

Figure 6. Correlation matrix for the first model

Based on the correlation plots in model 1, the results show a positive and strong relationship between the gross profits, sale/turnover and total stockholder equity variables among all firms within the CRSP database. However, there is a negative and extremely weak relationship between the mall level sales per square foot and the Gross profit, sales/turnover and total stockholder equity (-0.03, -0.02 and -0.05 respectively) of other retail companies (SIC Code: 5200-5990), consumer electronics companies (SIC Code: 7629), REITs (SIC Code: 6798), and multinational commercial Real Estate firms (SIC Code: 6512).

\subsection{Model 1 Testing}

In order to evaluate the hypothesis, this researcher uses the linear regression model to test the variable of mall store sales per square foot against gross profit, sales/turnover, and total stockholder equity. In order to optimize this model, this researcher excludes net sales turnover. The following outputs for the coefficients of correlation are displayed in Figure 7. 


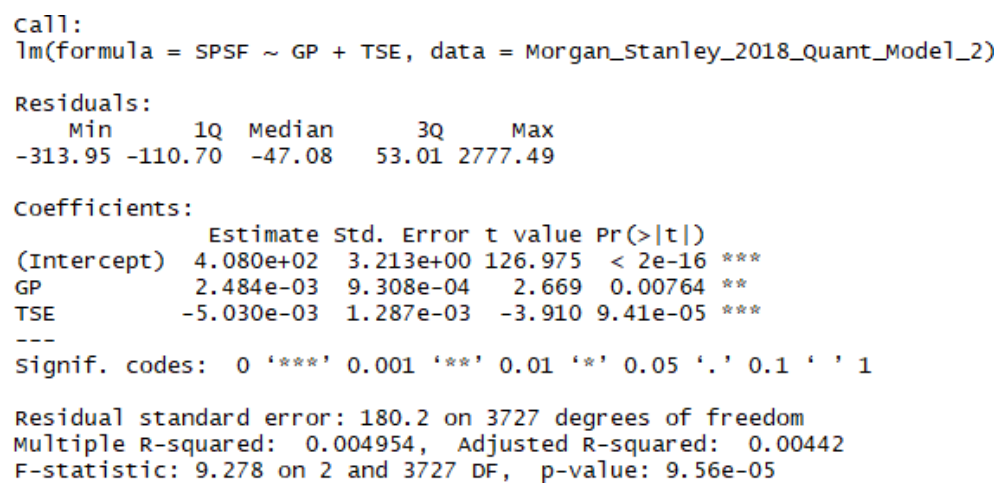

Figure 7. Linear regression model for the first study

Based on the results in Figure 7, this researcher can conclude that the independent variables of Gross profit and total stockholder equity in corporate companies can be trusted and accepted in this model. However, the adjusted R squared, shown in Figure 8, is extremely low which indicates that the points within this model are not displayed in a uniform manner.
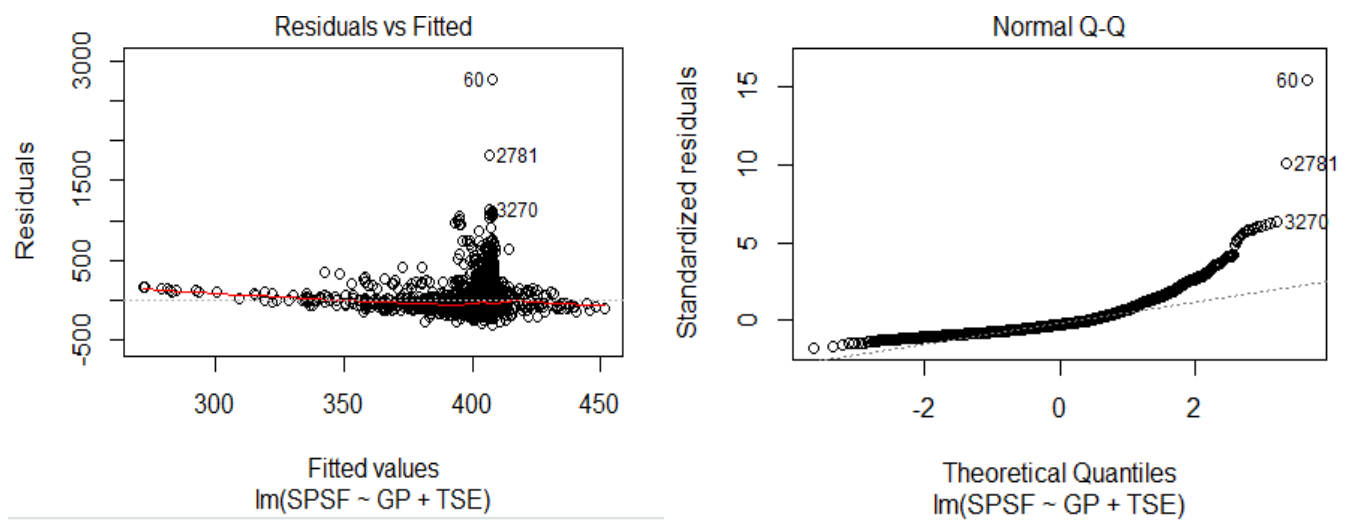

Figure 8 . Residuals vs. fitted values and theoretical quantiles of the first model

The final model that measures the performance of the mall against the performance of various other corporations is: $\mathrm{Y}($ Mall Level Sales PSF $)=\beta 0+$ Gross Profit - Total Stockholder Equity $+\dot{\varepsilon}$

This researcher suggests that additional exploratory variables can increase the accuracy and precision of this model. Since there are some inconsistencies within this model, this researcher implements model 2 (Mall Performance vs. Retail Stores and Restaurant Performance) to try to establish better results in this project.

4.5 Descriptive and Inferential Statistics for Model 2: Mall SPSF vs. the Performance of E-commerce Companies, Retail Stores, and Restaurants

This section of the paper covers the overall statistics for the second study that involves the examination of mall performance, e-commerce, retail stores, and restaurants.

4.5.1 Descriptive Statistics - Model 2 (E-commerce Companies, Retail Stores, and Restaurants)

The key variables include the mall level sales per square feet, the retail and e-commerce companies' sales per square foot, total revenue, retail sales per store and social media presence. The following code and diagram for this model are listed below:

\subsubsection{R Code: Descriptive Statistics (Model 2)}

\#\# Summary of Descriptive Statistics for the second Model

Summary (Morgan_Stanley_2018_Quant_Model_2) 


\begin{tabular}{|c|c|c|c|c|}
\hline \multicolumn{2}{|c|}{ MSPSF } & ASPSF & TR & RSSG \\
\hline Min. : & $: 246.0$ & Min. : 0.0 & Min. : & Min. $\quad:-0.160000$ \\
\hline 1st Qu. : & $: 376.0$ & 1st Qu.: 259.7 & 1st Qu.: & 1st Qu.: 0.000000 \\
\hline Median : & $: 484.0$ & Median : 448.2 & Median: 2540.0 & Median : 0.000000 \\
\hline Mean & $: 546.3$ & Mean : 448.2 & Mean : 10843.1 & Mean : 0.006119 \\
\hline 3rd Qu. : & $: 648.5$ & 3rd Qu.: 509.6 & 3rd Qu.: 10843.1 & 3rd Qu. : 0.020000 \\
\hline \multirow[t]{2}{*}{ Max. } & $: 1528.0$ & Max. $: 5159.1$ & $\operatorname{Max} . \quad: 485873.0$ & Max. : 0.340000 \\
\hline & & DSMP & & \\
\hline Min. : & & $: 0.00$ & & \\
\hline 1st Qu. : & 1515 & 1st Qu. : 15.57 & & \\
\hline Median : & 3602 & Median : 37.02 & & \\
\hline Mean : & 6406 & Mean : 54.51 & & \\
\hline 3rd Qu. : & 6406 & 3rd Qu.: 54.51 & & \\
\hline Max. & $: 154865$ & Max. $\quad: 531.81$ & & \\
\hline
\end{tabular}

Figure 9. Outputs for the descriptive statistics of model 2

Note: MSPSF = Mall Sales per Square Foot, ASPSF $=$ Individual Retail Store/ Restaurant per Square Foot, TR = Total Revenue), RSS = Retail Store Sales, RSSG = Retail Store/ Restaurant Sales Growth (in percentages), ASSR = Average Sales per store/ restaurant, DSMP $=$ Digital/ Social Media Platform

Based on the results above, this researcher concludes that social media plays a big role in the marketing component of each individual store performance.

4.5.3 Inferential Statistics- Model 2 (Mall Performance vs. Individual Store/ Restaurant Performance)

The following diagram below display the scatter plots for this model:

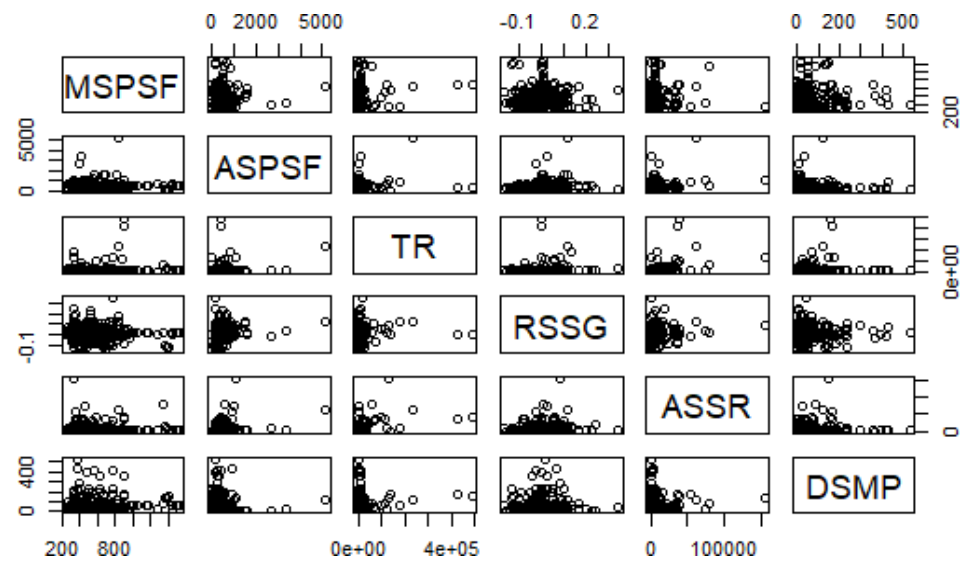

Figure 10. Scatter plot of variables in the second study

Based on the initial observation of this model, this researcher can conclude that the mall level sales per square foot are closely associated with the overall performance of individual companies, e-commerce businesses, and restaurants. For further evaluation, this researcher inspects the individual variables with respect performance: The following code in section 4.5.4 activates a correlation plot displayed in Figure 11.

\subsubsection{R Code: Visual Inspection of Variables in the Second Model}

library(quantmod)

library (Hmisc)

library(psych)

pairs.panels(Morgan_Stanley_2018_Quant_Model_2, color = "green")

\#\# Correlation Plot in multiple regression analysis

library(corrplot)

ms <- cor(Morgan_Stanley_2018_Quant_Model_2)

$\operatorname{view}(\mathrm{ms})$ 
The following inspection in Figure 11 displays a positive (but weak) correlation between mall level performance and all individual variables of each individual retail stores, e-commerce businesses and restaurants that are most likely tenants within these malls:

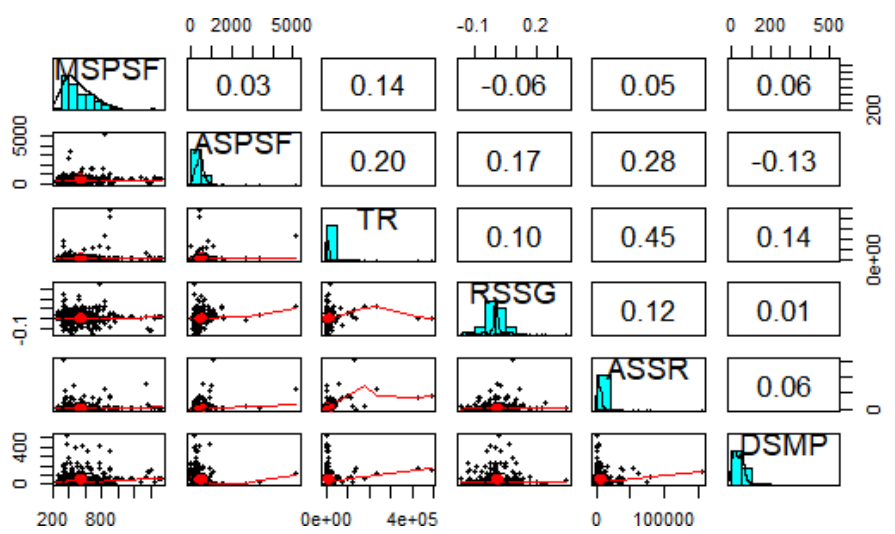

Figure 11. Distribution correlation plots for Model 2

This researcher notices a skewed distribution in the mall level sales per square foot, total revenue, and digital/social media presence as opposed to the normal distribution in this model. Therefore, the relationship between the mall level sales per square foot will not appear to be as strong as expected:

Table 3. Numerical correlation plots for model 2

\begin{tabular}{|r|l|l|l|l|l|l|}
\hline & MSPSF & ASPSF & TR & RSSG & \multirow{2}{*}{ ASSR } & DSMP \\
\hline MSPSF & 1.00000000 & 0.03191474 & 0.14449011 & -0.06180825 & 0.05264622 & 0.05613504 \\
\hline ASPSF & 0.03191474 & 1.00000000 & 0.19881871 & 0.17439160 & 0.27715153 & -0.12820697 \\
\hline TR & 0.14449011 & 0.19881871 & 1.00000000 & 0.09553525 & 0.44766646 & 0.14127363 \\
\hline RSSG & -0.06180825 & 0.17439160 & 0.09553525 & 1.00000000 & 0.12246723 & 0.00548661 \\
\hline ASSR & 0.05264622 & 0.27715153 & 0.44766646 & 0.12246723 & 1.00000000 & 0.06470286 \\
\hline DSMP & 0.05613504 & -0.12820697 & 0.14127363 & 0.00548661 & 0.06470286 & 1.00000000 \\
\hline
\end{tabular}

Note: MSPSF $=$ Mall Sales per Square Foot, ASPSF $=$ Individual Retail Store $/$ Restaurant per Square Foot, TR $=$ Total Revenue), RSSG = Retail Store/ Restaurant Sales Growth (in percentages), ASSR = Average Sales per store/ restaurant, DSMP = Digital $/$ Social Media Platform

\subsection{Model 2 Regression Analysis}

Initially, this researcher utilizes all variables that were available.in this portion of the study. Based on these results, a conclusion can be made that the average sales per store/restaurant (ASSR) is not a trusted variable in this model. This researcher argues that the implementation of the ASSR will reject the original hypothesis-accepting the null hypothesis. This researcher also notices that the R-squared measure is low. The low R-squared measure the fact that the data is not closely fitted in this regression model.

The possible reasons for this low R-Squared data are because distinct restaurants do not have retail store information and stores do not have any information on restaurants. Also, E-Commerce businesses like Amazon do not have any physical information regarding the physical location of the retail stores and restaurants. Therefore, the data set will not contain a high number of the coefficient of determination. In order to strengthen the relationship of this model, this researcher modifies this model by erasing the ASSR variable.

The coding for this output is available below: 


\subsubsection{R Code for Regression Model (Best Fit)}

Call: $\operatorname{lm}($ formula $=$ MSPSF $\sim$ ASPSF + TR + RSSG +DSMP, data = Morgan_Stanley_Quant_Model_2)

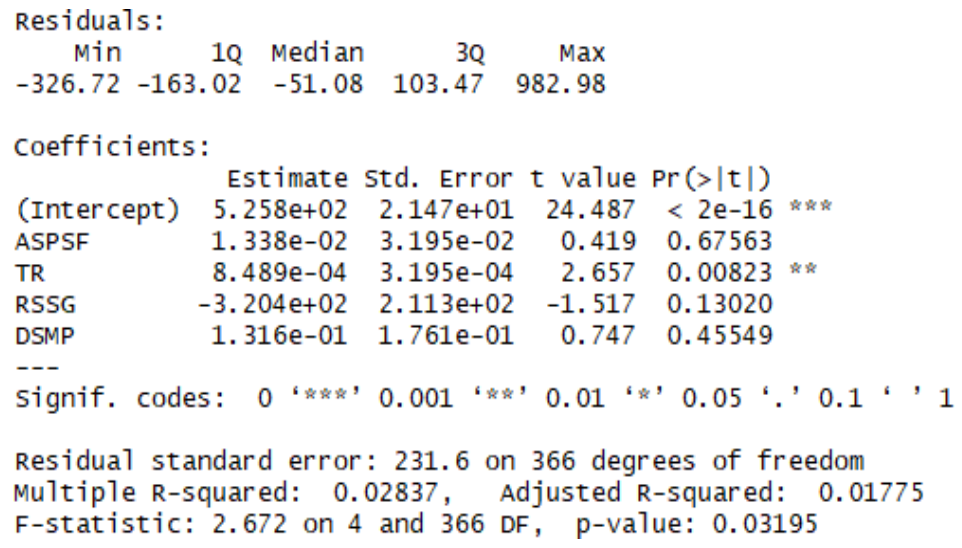

Figure 12. Outputs for the regression model of best fit

Based on the coefficients in Figure 12, the performance metrics between malls and all individual retail stores, e-commerce companies and restaurant is:

$$
\mathrm{Y}(\text { Mall Level Sales PSF })=\beta 0+\mathrm{ASPSF}+\mathrm{TR}-\mathrm{RSSG}+\mathrm{DSMP}+\dot{\varepsilon}
$$

Based on the results shown in Figure 13, this researcher can conclude that the model is not entirely linear and there is an abundant number of outliers in a portion of the project. This researcher also concludes that the exploratory variables support the initial hypothesis such that there is a positive correlation between mall performance and individual retail stores, e-commerce business and restaurants.
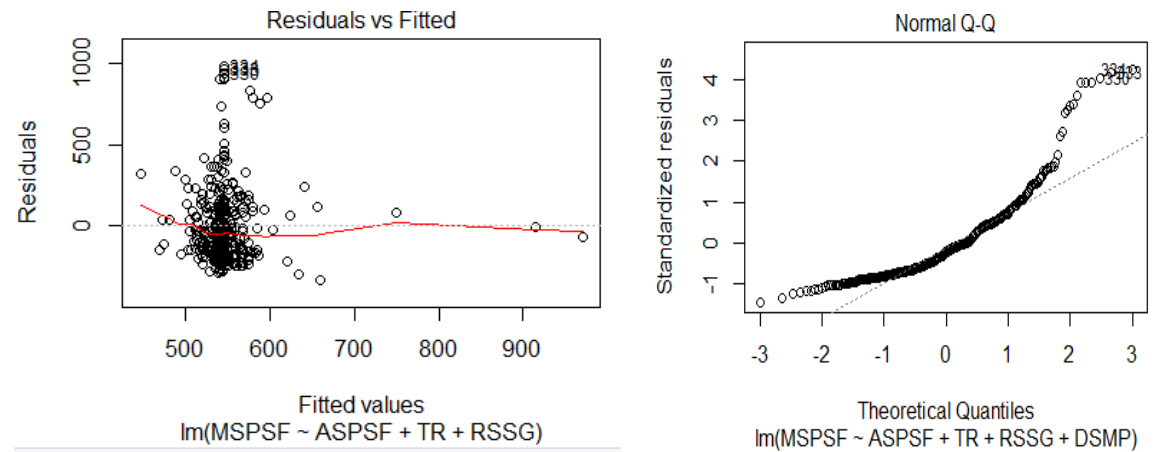

Figure 13. Residuals vs. fitted values and theoretical quantiles of the second model

\subsection{Scoring Measures}

This following code demonstrates a display of scoring metrics that measures the relationship between mall level sales per square foot and individual retail stores/ restaurants sales per square foot.

\subsubsection{R Code for Visual Scatter Plot (Performance Measures)}

\#\# Visual Scatter plot for performance measures

\#\# This line of code plots the mall slaes psf against all malls and restaurants

ggplot(Morgan_Stanley_2018_Quant_Model_2, aes(x = ASPSF + RSSG, y = MSPSF)) + geom_point()

\#\#This line of code adds color based on total revenue

ggplot(Morgan_Stanley_2018_Quant_Model_2, aes(x = ASPSF + RSSG, y = MSPSF, color = TR)) + geom_point $($ )

\#\#This line of coding add the size based on digital and social media presence

ggplot(Morgan_Stanley_2018_Quant_Model_2, aes(x = ASPSF + RSSG, y = MSPSF, 
color $=$ TR, size $=$ DSMP $))+$ geom_point ()

\#\# This line of code zooms in the $\mathrm{x}$ axis using a limit from 0 to 1,600 (excluding 3 outliers)

ggplot(Morgan_Stanley_2018_Quant_Model_2, aes(x = ASPSF, y = MSPSF, color $=$ TR + RSSG,

$\operatorname{size}=$ DSMP $))+$ geom_point ()$+\operatorname{geom} \_s m o o t h(s e=$ FALSE, method $=$ "lm" $)+x \lim (0,1600)$

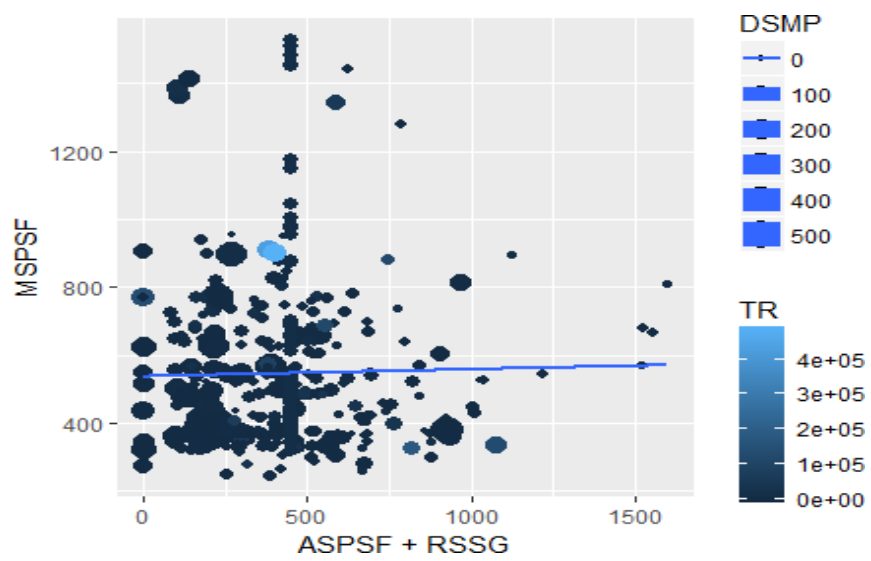

Figure 14. Outputs for performance measures

Based on the following diagram in Figure 14, this researcher can grade the overall mall performance using the different variables in this model. The following data in Table 4 decomposes the performance measures of each mall using a categorical rating from a D-grade to an $\mathrm{A}+$ grade.

Table 4. Performance metrics for malls and restaurants

\begin{tabular}{lll}
\hline Overall Performance Grades & $\begin{array}{l}\text { X-Axis Range (All Stores + Restaurants } \\
\text { RSSG + SPSF) }\end{array}$ & $\begin{array}{l}\text { Y-Axis Range (Mall Level } \\
\text { SPSF) }\end{array}$ \\
\hline A+ (97-100) & $700-1600$ & $1200-1600$ \\
\hline A (93-96) & $480-699$ & $1200-1600$ \\
\hline A- (90-92) & $300-479$ & $1200-1600$ \\
\hline B+ (87-89) & $700-1600$ & $800-1200$ \\
\hline B (83-86) & $480-699$ & $800-1200$ \\
\hline B- (80-82) & $300-479$ & $800-1200$ \\
\hline C+ (77-79) & $700-1600$ & $400-800$ \\
\hline$C(73-76)$ & $485-699$ & $400-800$ \\
\hline$C-(69-72)$ & $250-484$ & $400-800$ \\
\hline D (65-69) & $0-249$ & $0-400$
\end{tabular}

Note: The numeric grades are affected by the total revenue and the digital/social media presence.

Overall, this model shows a positive relationship between mall level performance and the performance of individual retail stores, E-Commerce companies and restaurants

\section{Conclusion}

This empirical study tests the relationship between mall level performance and corporate performance. This study also examines the relationship of mall performance against the performance of individual retail stores and restaurants. The results of the first model in this paper show a negative relationship between mall performance and corporate performance within various industries. The results of the second model in this paper generally show a positive 
correlation between mall performance and the performance of individual retail shops and restaurants. Additionally, this paper establishes a performance metric between malls and individual shops and restaurants. The tranche measures the consistency of mall level sales per square foot against the individual store average sales per square foot, total revenue, retail store/restaurant sales growth and digital/social media presence.

This study suggests that mall level performance is not entirely indicative of stock market performance. Based on the economic environment, consumers will continue to shop for products that are inelastic. This study also suggests that customers do pay attention to digital/social media presence in order to make a sound judgment on certain retail products and customer loyalty. If the products have good reviews from consumers, there will be a higher retention behavior towards these products- leading to a strong performance among retail tenants within shopping centers and malls.

This study has several limitations. This researcher relies on administrative data that is pulled from a portal. Therefore, the results are limited by the accuracy of this data. The samples in each variable have is subjectively collected and the dataset does not provide much geographical information of each individual store. This limitation may lead to errors in terms of measuring the control variables of location and competition. For a complete generalization of results, this researcher recommends testing additional geographical information within the project.

This study also contains a limited number of variables that measure corporate valuation. For future research, this researcher recommends additional quantitative and qualitative variables that talk about the free cash flow and economic value of each shopping mall. This researcher also recommends implementing additional control variables within the spectrum of demographic characteristics in each mall. For example, this research project lacks information regarding the number of households, median income and the age of the consumer market. Although there are certain limitations and implications, this empirical study proves the notion that mall level performance has an effect on corporate performance. This study also proves that mall performance has a positive relationship within individual retail performance.

\section{Acknowledgements}

I would like to thank the entire Quantitative Finance Division at Morgan Stanley for selecting this paper as a finalist for the 2017-2018 Morgan Stanley Quantitative Finance Prize for Excellence Contest.

\section{References}

Anderson, C. (2006). The Long Tail: Why the Future of Business Is Selling Less of More. Hyperion: New York, NY

Banerjee, S. (2017). From Mall Madness to Sadness: Why Shopping Centers will soon be Obsolete.

Berger, J. (2017). How to be more influential. Credit Union Management, 40(10), 24.

Downloading 10-K filings from SEC's EDNAR. (n.d.) Retrieved from http://www.wrds.us/index.php/tutorial/view/26

E-commerce Trends and Store Sales for Top Retailers (Retail). (2018). eMarketer.Retail. Retrieved from https://retail-index.emarketer.com/dashboard/c/retailers/5374f2454d4afd824cc15571/ttm/AllCompanies/All\%2 OSectors

Hudson, M. (2017). 8 Ways to Measure Retail Productivity and Performance. The Balance.

Marbury, D. (2017). Keeping up with consumer demands. Managed Healthcare Executives, 27(5), 12-14.

Nicasio and Stanley. (2011). Key Performance Indicators- 10 Metrics for guiding and measuring and measuring store success. Vend. Retrieved from https://www.vendhq.com/images/university/retail-kpiguide/Key_Performance_Indicators.pdf

Ramsey, R. (1994). Retail sale data and the evaluation of major retail centers. Appraisal Journal, 62(4). Retrieved from http://www.freepatentsonline.com/article/Appraisal- Journal/16396560.html

Sanicola, L. (2017). America's mall is roting away. CNN Money. Retrieved from http://money.cnn.com/2017/12/12/news/companies/mall-closing/index.html

Six Factors that determine a Tetail Mall's Success. (n.d.). TVS Designs. Retrieved from http://www.tvsdesign.com/six-factors-that-determine-a-malls-success/ 